\title{
CASE STUDIES: IN-SITU REBUILDING OF DAMAGED ROPE DRUM SHAFTS OF SSG CRANE AND THE REPAIR OF CIRCUMFERENTIAL CRACK OF CEMENT KILN BY WELDING.
}

\author{
Joseph Runyoro \\ Engineering Materials Department, College of Engineering and Technology, University of Dar es salaam, \\ P.O. Box 35131, Dar es Salaam, Tanzania.TEL: +255754304729, Email: owekisha@ uccmail.co.tz
}

\begin{abstract}
Material failures in engineering are characterized by unwanted downtime of equipment and require the application of sound engineering principles to rectify the problem so that it does not reoccur. The most widely method for repairing damaged steel structures such as rope drum shaft or cracked cement kiln is by Manual metal arc welding. The equipment mentioned have their main importance that, when they are broken down, they cost a lot of money in lost revenue and affects a lot of people in terms of business and livelihood. The nominal diameter $(D N) 240$ rope drum shaft was damaged when the roller bearing failed and abraded the shaft bearing journal in such a way that the diameter decreased. The solution was either to order the new shaft, or repair the existing shaft in workshops with lathe machines capable of accommodating it. Ordering the new one will have taken a long time to deliver. Installation process would have been costly taking into consideration the position of the hoist drum being at a height of over 40 meters above the ground, and no crane was available in the country with required capacity. The remaining and immediate solution was to repair the damaged bearing journal in-situ. The paper describes how the repair was carried out successfully, and has been in operation since 1995. Recently, another failure of the same nature occurred on another equipment in which the same assistance were sought. In 1994, the cement kiln was found to have a $270 \mathrm{~mm}$ length circumferential crack on a $65 \mathrm{~mm}$ thick plate which needed urgent repair so that the production of cement can proceed while waiting for replacement. The immediate repair was necessary to avoid the bending of the kiln which would have caused uneven rotation and poor sealing of refractory bricks. The crack was on the cantilever section of the kiln which, if the crack was allowed to grow, would have caused the section with cooler tubes to snap off. The paper explains how the repair was carried out allowing the plant to operate for two years before segment replacement.
\end{abstract}

Key words: In-situ repair, ship to shore crane, cement kiln, shafts, In-situ machining, arc welding.

\section{INTRODUCTION}

A failure occurs in equipment when certain design, manufacturing or operating conditions are not met. There have been cases when a failure occurs; the management tends to procure a new spare part/ equipment instead of repairing the damaged part by welding even if it is repairable especially worn out parts. This trend is common in many industries, and its costs them a lot of money than that which they would have incurred in repairing the equipment in terms of downtime, loss of confidence from clients and lost revenue. The management may be shying away from repair by welding because of the bad experience that parts repaired by welding fails after a short period.

Failures are common when the right welding procedure and technique is not followed. For a successful repair, welding procedure has to be specified and qualified by technical welder to confirm the part with same chemical composition used in procedure qualification test, is repairable by the selected process and welding consumables. In welding of steels with thick cross section especially those with alloys or high carbon content, there is a need to carry out heat treatment of the metal in form of pre - and post heat treatment to make sure that hard structures such as martensite are not formed 
in the weld metal or in the heat affected zone. The welding consumables and weld joint surfaces have to be free of moisture to avoid hydrogen induced cold cracking and other moisture related defects. The weld joint has to be prepared such that lack of fusion and lack of penetration defects are avoided. All these precautions, when taken in consideration, will produce a sound weld. To quantify this, two examples are presented showing good workmanship in repairing of the equipment in high demand and critical in the nation's economy. The first case study is the Ship to Shore Gantry Crane (SSGC) capable of loading and unloading over 25 containers per hour. The Roller bearing failure occurred on the hoist drum shaft and damaged the bearing journal on the drive side. The one meter diameter hoist drum was located at height of over 40 meters above the ground. To lower it down from that height, a capable crane was not available in the country. Even if the exercise was successful, no lathe machine in the country would have accommodated the hoist drum. A solution was found which involved repairing the shaft in-situ. Unfortunately, recently, the other SSGC equipment damaged its bearing on the driven side of hoist drum shaft which required the same treatment as the first failure.

The second case study was of the cracked circumferential shell on a cantilever section of the cement kiln, just after the large mill roller but before the cooling tubes. Excessive heat caused the shell to bend, and cracked due to fatigue failure. The crack had to be repaired immediately by welding to avoid the refractory bricks to loosen and cause the shell to bend further due to overheating.

\section{CASE STUDY 1 RECONDITIONING OF DN 240 ROPE HOIST DRUM SHAFT OF A SHIP TO SHORE GANTRY CRANE.}

\section{BACKGROUND}

The Consultant was approached regarding the worn out bearing journal on the DN 240 shaft. The shaft is located on the hoist drum on 36 ton Ship to Shore Container Crane. The crane is used for moving container on and off container ships calling at Dar es Salaam port. The crane has been in service for over 18 years of continuous operation. The Dar es salaam port at present has three ships to Shore Gantry
Cranes capable of handling 20 to 25 containers per hour, and they can be used to load or unload a ship simultaneously. Otherwise up to three ships can be berthed to use these three cranes which work 24 hours per day, save for maintenance. The hoisting system is over 43 meters above the ground, a distance out of reach of available cranes at that time in Tanzania (Fig. 1).

The biggest crane was 150 Ton with the capability of hoisting 135 Ton at $5 \mathrm{~m}$ radius and with a maximum boom extension of $42 \mathrm{~m}$ carrying 15 Tons at $10 \mathrm{~m}$ radius and 5 Tons at $20 \mathrm{~m}$ radius (Fig. 2). In order to lower the drum, the boom extension should be at least $50 \mathrm{~m}$ in length. Even if it was brought down, there was no lathe machine in Tanzania capable of machining the part after welding.

The hoist drum was $6766 \mathrm{~mm}$ long and $1240 \mathrm{~mm}$ in diameter, a distance big enough not able to be handled with available lathe machines in Tanzania. The consultant was reminded that the crane was of prime importance to the nation, close to high season of business, and has to be repaired urgently. Therefore, at any cost, the machine was required to be put back into action to avoid long delays of ships at anchor outside the port. As the crane was grounded, time was of the essence to the owner of equipment. The broken bearing was ordered, but the new bearing can't be fitted unless the shaft is filled and machined to original size. The work involved rebuilding the shaft by welding with the right electrodes, machining and grinding to the bearing size in-situ.

Repairs of major equipment such as 36 ton capacity Ship to Shore Gantry Crane (SSGC) takes time, as they involve placing orders for the special fabrication of replacement parts from factories overseas followed by installations, which would have required the appropriate crane, ordered from abroad.

It is not the aim of this article to discuss why the bearing failed and caused such damage to the shaft without being noticed on time. It has to be taken into account that the main rope hoist drum is situated at the height of over 40 meters above the ground and the room is equipment with motors and gearboxes which makes a lot of noise. Therefore it would have 
been difficult to notice the noise caused by failing bearing. The methods used to monitor the bearings are monitoring of vibrations, temperature, noise (conditional monitoring) or by changing the bearing after a specified period of operation.
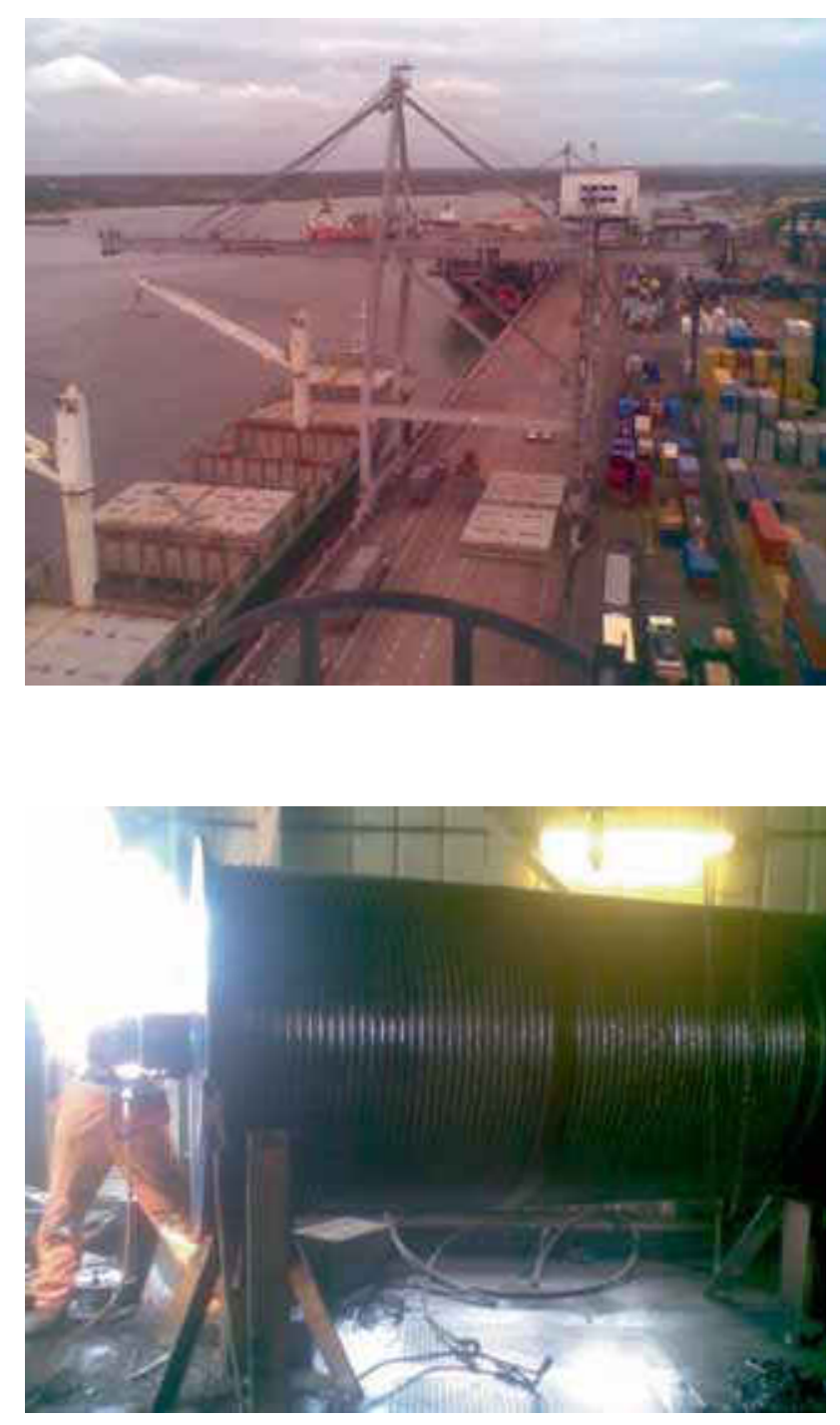

Fig. 1: at the bottom is the structure of SSG Crane showing a white box where the winching system in located. At the top is typical rope hoist drum, being repaired.

The terms of reference for successful repair of the shaft included carrying out shaft measurements and selection of bearing tolerances, to prepare Repair method statement, and liaise with companies capable of in-situ machining and polishing of the shaft journal, and the supervision of the work. The preparation of method statement required the input of the Crane Manufacturer.

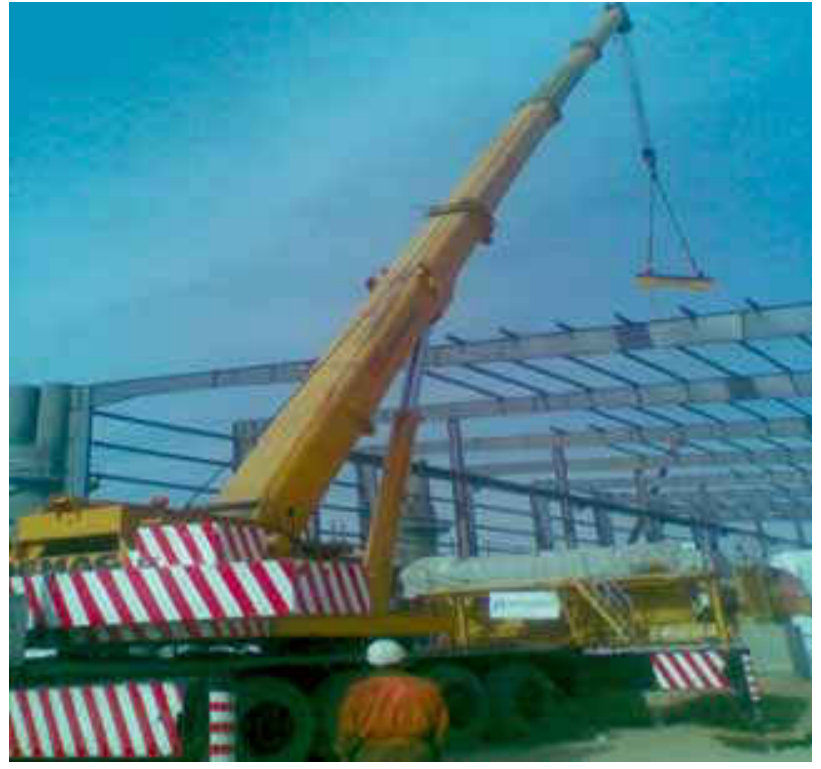

Fig. 2: The biggest crane available at that time was 150 Ton crane with the maximum boom span of $42 \mathrm{~m}$.

\section{Methodology}

The consultant sought for information from the crane manufacturer and researched on possible company which can carry out in-situ machining of the shaft. In the anticipation that the shaft can be rebuild locally preparation were made to carry out the work.

The procedure for rebuilding the worn out bearing seating on a shaft of the hoist drum of the crane was as follows. The damaged shaft was cleaned by grinding to prevent arc interference, weld metal contamination and possible porosity. Cracks and any deformations in the shaft were repaired before rebuilding. A grinder was used to remove any crack down to sound metal. Measurements were made by the use of vernier caliper on the damaged journal to assess the extent of rebuilding required on the shaft.

Methods considered for repairing worn shaft included; Welding and machining, Surface spraying / plating and grinding, Welding a slip on bush on the damaged surface and changing the bearing dimensions to carter for bigger bore hole, the use of bush bearing (it may be of split type) instead of ball bearing, or shift the existing position of the bearing to a new location were the shaft is still in good condition. All these options were studied in detail and an optimum solution was selected, that is rebuilding the worn out part by manual metal arc welding and machining. 
The negative welding cable was connected directly to the shaft end being welded to avoid arcing through other bearings of the equipment. The shaft was preheated and kept at a temperature above $105^{\circ} \mathrm{C}$ by the use of flame torch during the entire welding process. In case there was a break, the welded part was covered with the insulation material to minimize the fast cooling of the weld metal.

In the rebuilding, transverse beads were deposited by skip weld process to balance the heat dissipation on the shaft and avoid bending. Beads were deposited at different locations around the circumference of the shaft until the entire shaft was filled. The skip weld process was repeated until successive spaces between the original beads were gradually closed in and the entire center area of the shaft overlaid. After the first layer was built up the same procedure using transverse beads was used to fill the damaged journal. Skip welds process provided proper heat distribution, minimizing thermal stresses. The electrodes used for rebuilding of the worn shaft were low hydrogen electrode of the type E 7018-1. These are suitable for welding high strength low alloy steels, as they are very resistant to hot cracking. After welding, the built-up part was heated at a temperature of around $150^{\circ} \mathrm{C}$ to remove residual stresses before machining to the final size.

\section{FINDINGS AND DISCUSSIONS}

The bearing failure may have been caused by fatigue failure of one of the bearing parts, interfering with the movement of other rollers and damaging other parts of bearing housing and generating very high temperatures within the bearing due to friction between the broken bearing parts. This in turn will have caused wear on the shaft's bearing seat.

The authors took a sample of the shaft material for chemical analysis to identify proper procedure for carrying out the repair of the worn out shaft. At the same time, the manufacturer of the Crane was notified about the problem and was requested to supply the information of how to repair the shaft. The information requested included shaft chemical composition and heat treatment if any, carried out on the shaft prior to assembling of the hoist drum. The information was necessary to assist the client on decision making of either repairing the shaft or ordering a complete new hoist drum.
The manufacturer recommended not welding the shaft as it would pose safety risk in the future and the quotation for rope drum or with assembly was attached. Further discussions with rope drum manufacturer suggested that it was dangerous and very difficult to replace the flange only, and re-welding of the shaft was very dangerous as the shaft can be damaged due to welding work. If the repaired shaft fails, the container load can drop down from height uncontrollably causing damage to other equipment and personnel. So the manufacturer insisted on replacing compete drum with bearing housings or the rope drum. The manufacturer was requested to state the delivery time, methodology of removing the defective part or whole rope drum, special tools and equipment required, if the manufacturer will supervise the work and how long will it take to commission the crane back into service.

The manufacturer informed client that manufacturing of the rope drum involves machining the drum tube first, followed by welding both end flanges on the ready machined drum tube, and final machining of shafts and flanges to guarantees straightness of shafts and tube followed by balancing of complete drum. They did not recommend repairing the shaft locally and needed to carry the repair work themselves. The fees for mechanical supervisor were put at EUR 700 per day excluding flights, hotels and other costs. While waiting decisions from the client to order new drum, the manufacturer provided the shaft material to be BS $436050 \mathrm{C}$ and strongly recommended not to weld the shaft because it may form cracks after welding. The type of material corresponded with the chemical analysis already taken locally. It was recommended by the consultant that the shaft can be rebuilt locally by welding without any significant problem.

The go ahead was given to rebuild the worn out shaft so that if possible, the equipment operates for at least one year, giving enough time for ordering a replacement. It was the work of the consultant to determine the company to carry out the machining of the shaft after welding. It was realized that very few companies in the world carry out in-situ machining of components. Through research the consultant was able to locate one company in South Africa specializing in this field namely M/s Machine Cutting Services (Pty) Ltd. Information was sent to 
the company informing them the extent of failure. One of the hoisting rope drum bearing on the drive side failed by cracking into small pieces and has worn down the shaft up to $239.80 \mathrm{~mm}$. The required size was between 240.079 and 240.057 in diameter so that the bearing can fit. The distance of the drive end shaft to the center of the bearing was $840 \mathrm{~mm}$, and the thickness of the bearing was $60 \mathrm{~mm}$. (Fig. 3). The procedure for building up of the worn out part was proposed and was approved by the client and the machinist.

The chemical composition analysis of the shaft material confirmed that the material was BS $436050 \mathrm{C}$ material, but due to its size, it needed preheating in order to weld without the possibility of cracking. The E 7018-1 type of electrodes with basic coating and with extra low moisture content and good resistance to moisture pickup was selected. It is suitable for welding high tensile steels sensitive to hydrogen embrittlement. These include hardenable low alloy structural steel and carbon steel particularly when preheating cannot be used or when the moisture content of the coating is critical. It was proposed that the shaft be rebuild using $3.2 \mathrm{~mm}$ diameter, E 70181 stick electrodes with electrode connected to DC $+v e$. The selection of the rectifier and electrodes was based on the fact that low heat input was preferred to minimize shaft distortion, cracking, and hard deposited weld metal due to carbon pick-up from the parent metal (Table 1). The transverse welding taken along the axis of the shaft is superior in fatigue properties than circumferential welding, as if there is any weld metal crack formed during the welding process, it will be difficult to propagate in transverse welded metal as compared to the transverse one.

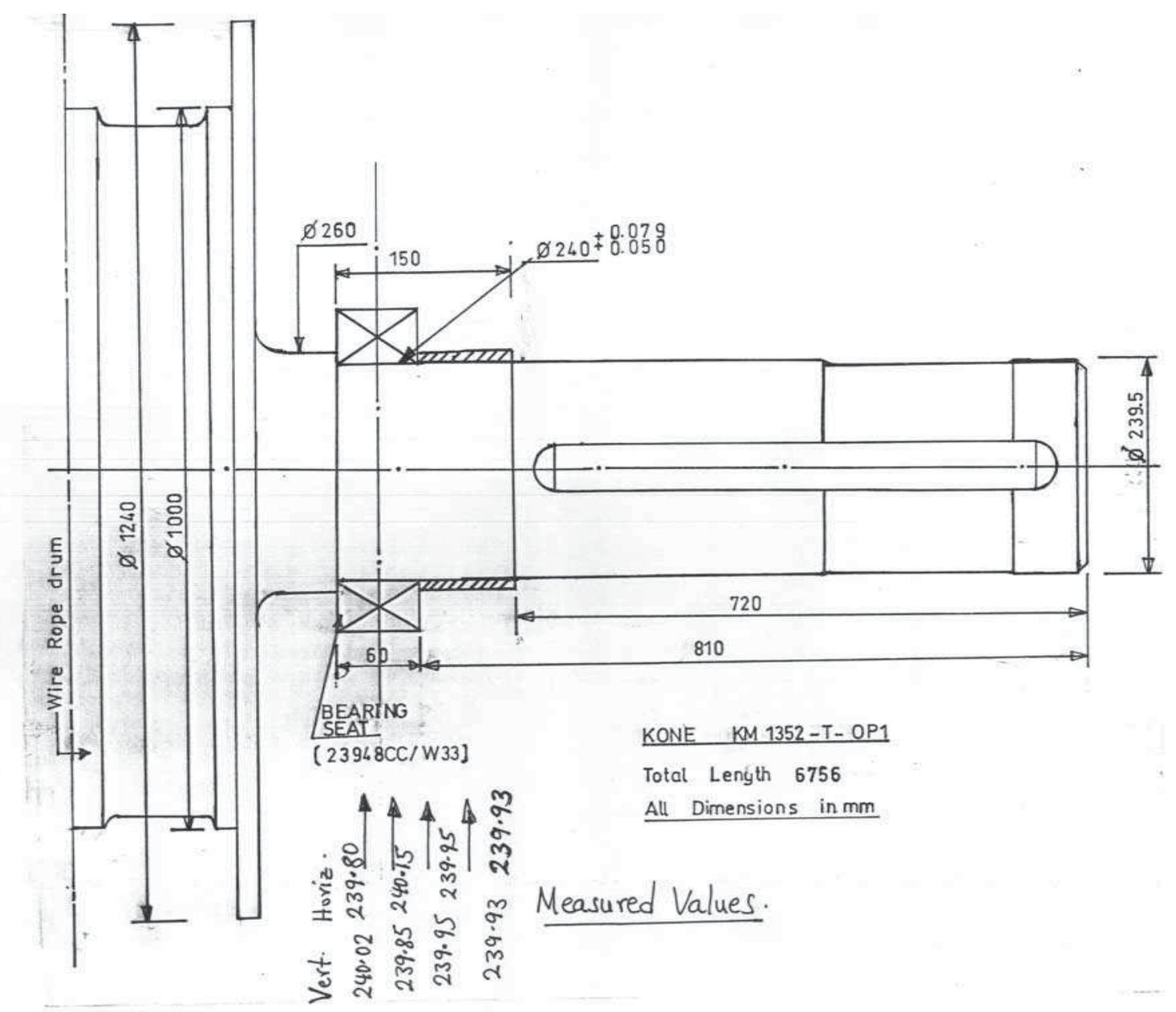

Fig. 3 Sample of drawing sent to the machinist so that the right machining equipment can be selected 
The shaft was machined and the bearing seat ground to the accuracy of k6 tolerance as shown in Table 2. The bearing was assembled and the equipment is in working order since then. Recently, another bearing on the driven side of the rope hoist drum failed as shown in Fig. 4. The damaged shaft was welded using the same procedure as that used in the first failure, and machined as shown in Fig. 5. The same machine used for machining can also be used for grinding the bearing seat. The type of the machine depends on the nature and surface to be machined. The machine used in this work is as shown in Fig. 5a. The machine used in the previous repair is as diagrammatized in Fig. 6. They are all air operated and it is more of milling process than machining as the work piece is stationary. The main problem of this type of in-situ welding of the shafts is the alignment. If the alignment is not proper, the shaft will be rotating unbalanced and will fail prematurely under fatigue mode.
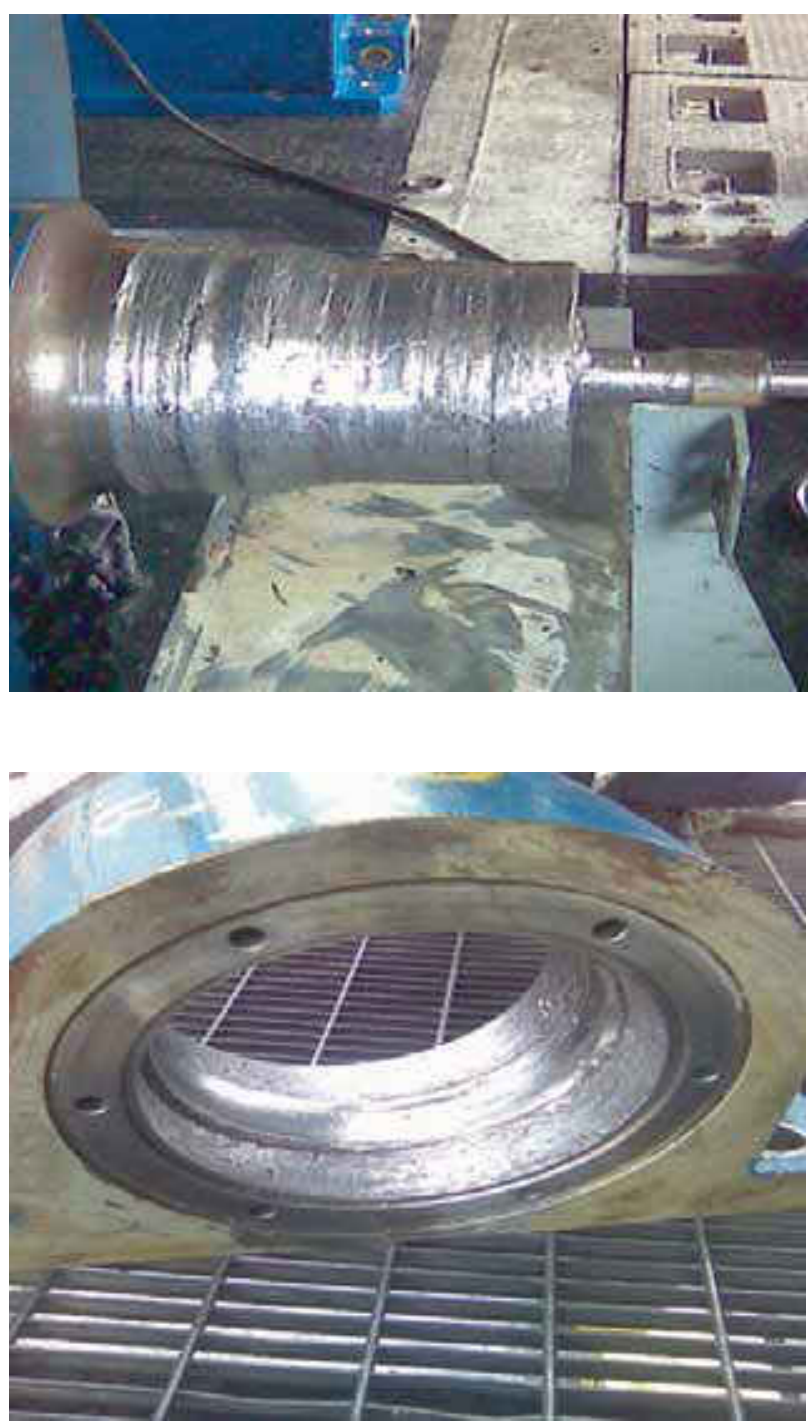
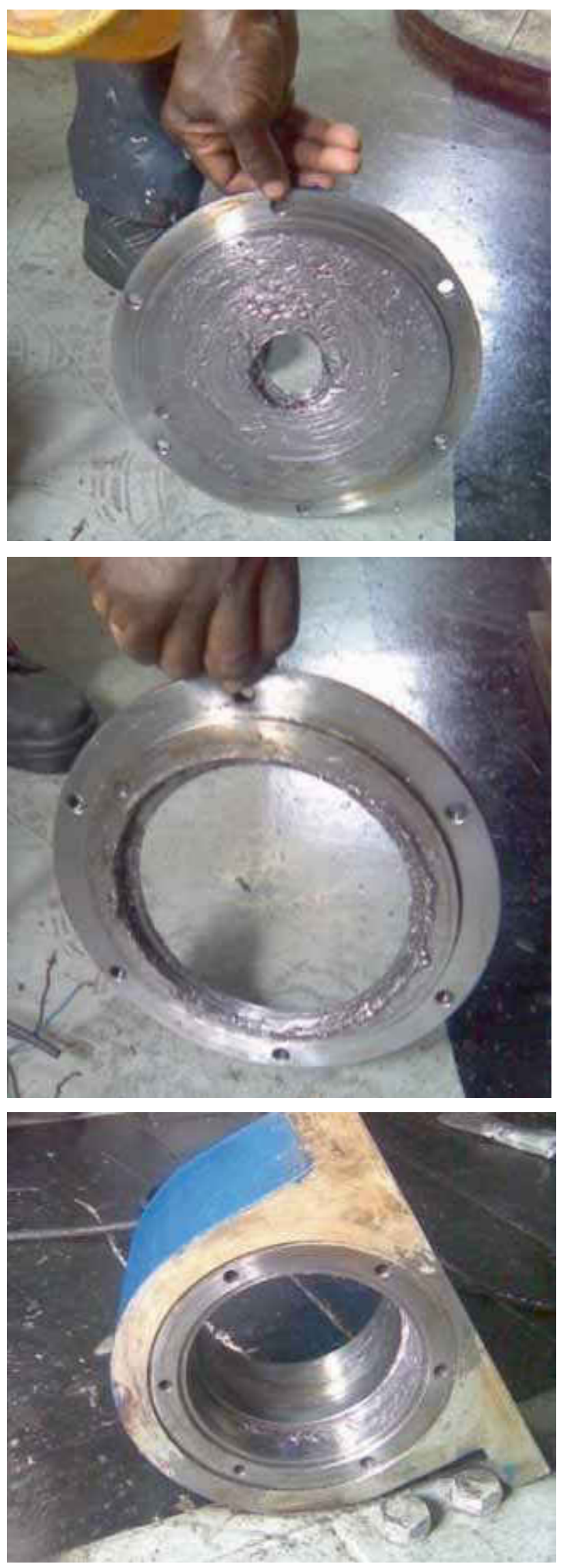

Fig. 4: Damaged main rope hoist drum shaft with bearing journal and covers. 


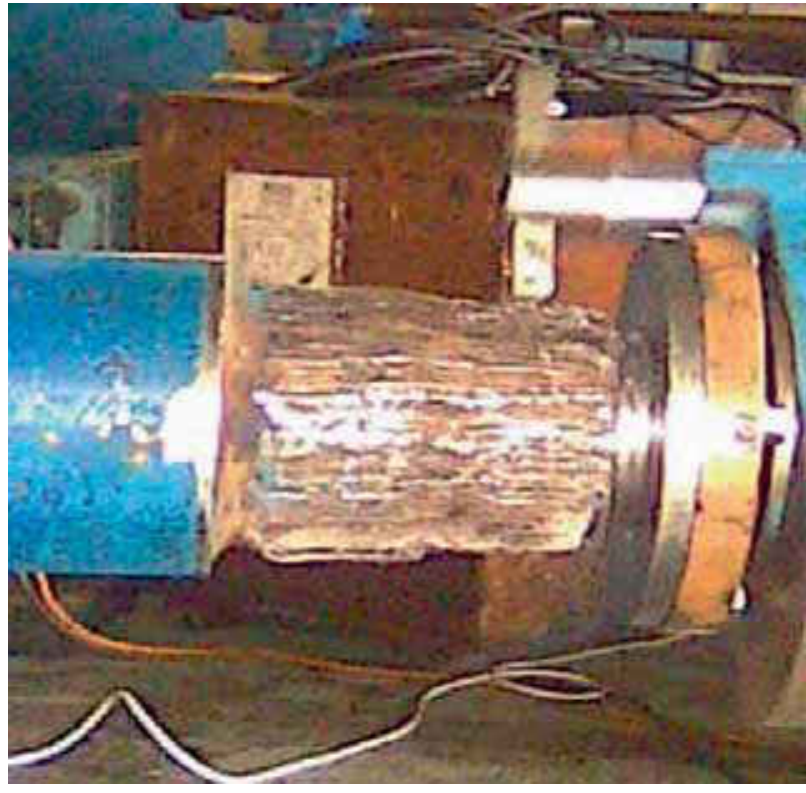

A)

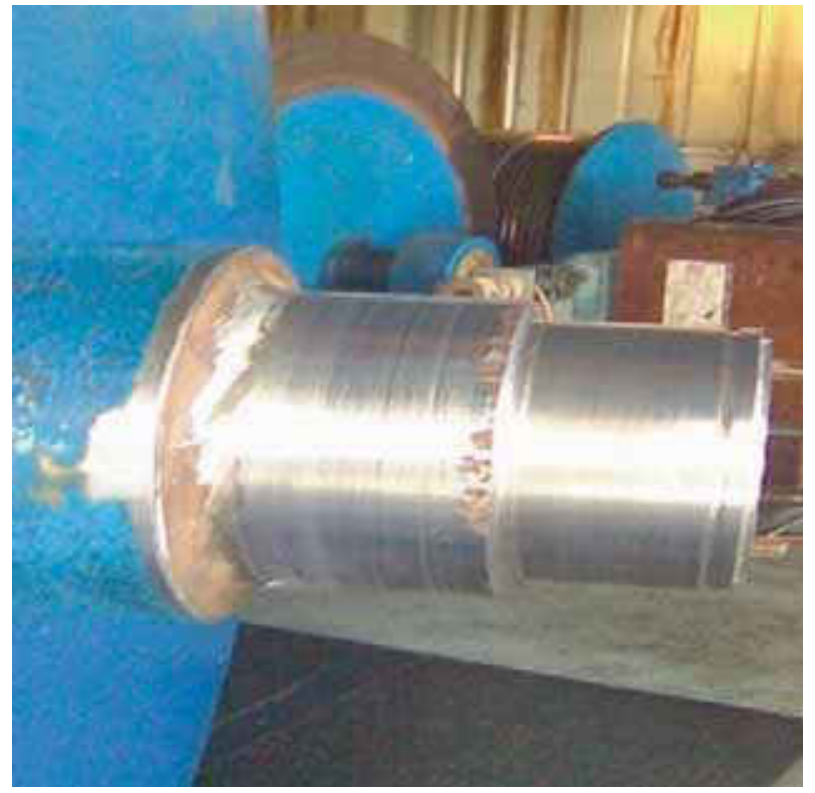

B)

Fig. 5: Rebuilding by welding and machining of rope hoist drum shaft

Table 1 Typical chemical composition and mechanical properties of shaft material and basic electrodes.

\begin{tabular}{|l|l|l|l|l|l|l|l|}
\hline Material & \multicolumn{4}{|c|}{ Typical chemical analysis } & \multicolumn{3}{c|}{ Mechanical Properties (MPa) } \\
\hline & $\% \mathrm{C}$ & $\% \mathrm{Si}$ & $\% \mathrm{Mn}$ & $\% \mathrm{Mo}$ & $\mathrm{S}_{\mathrm{y}}$ & $\mathrm{S}_{\Gamma}$ & $\% \mathrm{El}$ \\
\hline $50 \mathrm{C}$ & 0.20 & 0.50 & 1.5 & & 345 & $490-620$ & 20 \\
\hline $55 \mathrm{C}$ & 0.22 & 0.60 & 1.6 & & 430 & $550-700$ & 19 \\
\hline E 7018-1 & 0.07 & 0.50 & 1.4 & & 480 & 590 & 28 \\
\hline E7018-A1 & 0.06 & 0.50 & 0.70 & 0.5 & 460 & 560 & 27 \\
\hline & & & & & & & \\
\hline & & & & & & & \\
\hline
\end{tabular}

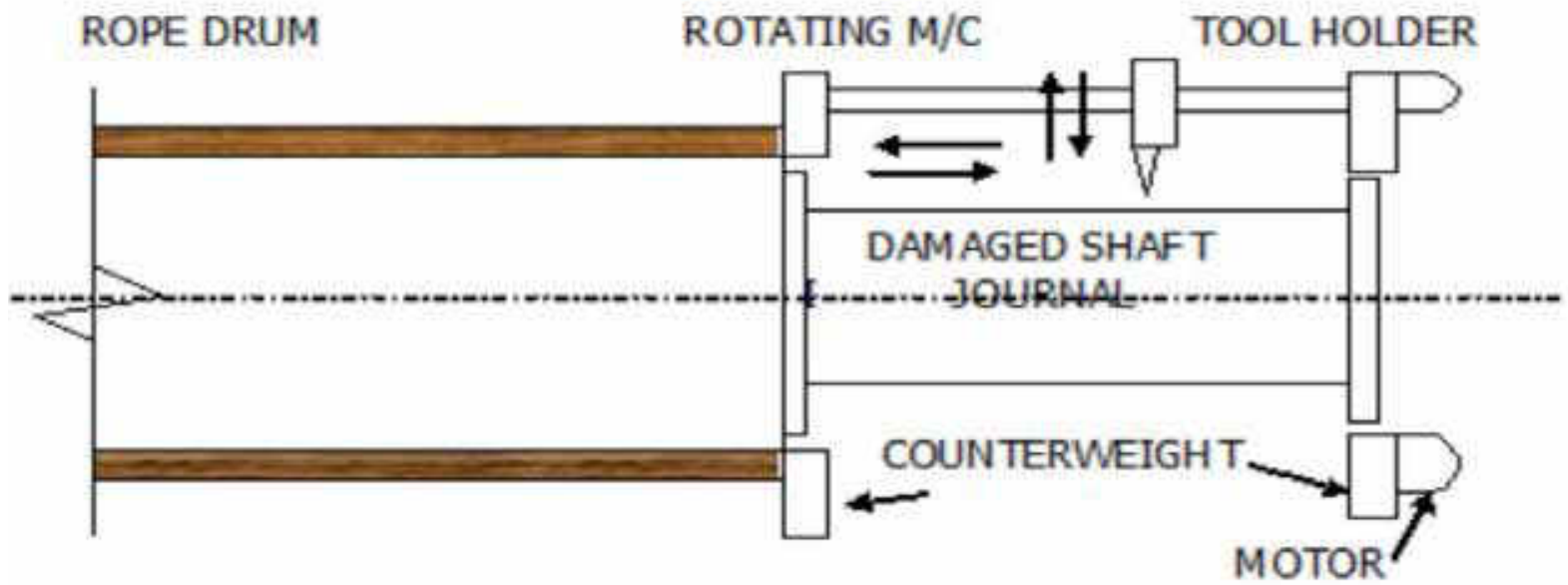

Fig. 6: Typical arrangement of air powered milling machine for turning the rebuilt by welding long shaft with a bearing journal 
Table 2 Recommended fit for Bearing $240 \mathrm{~mm}$ with 0 to (-) $0.03 \mathrm{~mm}$ tolerance. T indicates tight fit and $L$ indicates loose fit.

\begin{tabular}{|l|l|l|l|l|l|l|}
\hline & \multicolumn{2}{|c|}{ Shaft Dia (mm) } & \multicolumn{3}{c|}{ FIT } \\
\hline \multicolumn{1}{|c|}{ Series } & \multicolumn{1}{|c|}{ Max } & \multicolumn{1}{c|}{ Min } & \multicolumn{2}{c|}{ Low } & \multicolumn{3}{c|}{ High } \\
\hline j6 & 240.015 & 239.987 & 0.015 & L & 0.046 & L \\
\hline k5 & 240.022 & 240.005 & 0.005 & T & 0.053 & T \\
\hline k6 & 240.035 & 240.005 & 0.005 & T & 0.066 & T \\
\hline m5 & 240.038 & 240.017 & 0.018 & T & 0.069 & T \\
\hline m6 & 240.045 & 240.017 & 0.018 & T & 0.076 & T \\
\hline n6 & 240.060 & 240.030 & 0.030 & T & 0.091 & T \\
\hline p6 & 240.078 & 240.050 & 0.051 & T & 0.109 & T \\
\hline r6 & 240.111 & 240.083 & 0.084 & T & 0.142 & T \\
\hline r7 & 240.129 & 240.083 & 0.084 & T & 0.160 & T \\
\hline
\end{tabular}

\section{Conclusions:}

1. The damaged shaft for rope hoist drum was rebuilt by welding, machined and the journal ground to size of the bearing, in-situ. The repaired shaft has been in service since 2005 .

2. The same failure occurred in the other rope hoist drum of shore to ship Gantry Crane recently, and was successfully repaired using the same procedure.

\section{CASE NO 2. WELDING OF THE CIRCUMFERENTIAL CRACKS OF WELDED JOINT OF THE CEMENT KILN}

\section{BACKGROUND}

In 2002, the Cement Kiln with 3.95 m diameter and $65 \mathrm{~m}$ in length shown in Fig. 7, generated a circumferential crack during its operation on an overhang carrying twelve planetary coolers. The opening in the hollow shaft was detrimental in the operation of the Kiln as it would have bent and caused uneven rotation, and causing misalignment of refractory bricks. In turn the clinker heat would have penetrated through the gap between the refractory bricks and heating up the kiln steel plates, which would have caused further buckling and failure.

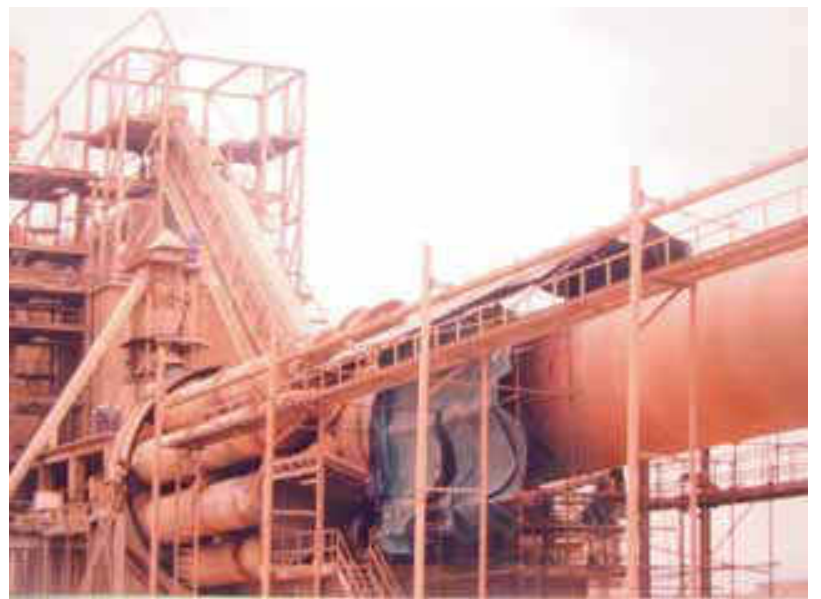

Fig. 7: Typical arrangement of air powered milling machine for turning the rebuilt by welding long shaft with a bearing journal

The factory produces cement which is made by heating limestone to produce calcium oxide with small quantities of other materials (such as sand, shale, clay, and iron) in a process known as calcination. The kiln feed is fed to a preheater tower, which is 150 meters high. Material from the preheater tower is discharged to a rotary kiln. The preheater tower and rotary kiln are made of steel and lined with special refractory materials to protect them from the high process temperatures. The rotary kiln is fired with an intense flame of up to $1450^{\circ} \mathrm{C}$ temperature, produced by burning coal or coke. The rotary kiln discharges the red-hot clinker under the intense flame into a clinker cooler. The clinker is stored on site in silos until needed for cement production. Clinker, 
gypsum, pozzolan and other process additions are ground together in ball mills to form the final cement products with the majority of the materials having less than 75 microns. Fineness of the final products, amount of gypsum added, and the amount of process additions added are all varied to develop a desired performance in each of the final cement products. The most common use for cement is in the production of concrete. Concrete is a composite material consisting of aggregate (gravel and sand), cement, and water.

\section{METHODOLOGY}

All circumferential welded joints were inspected to determine precisely the limits of the crack using visual, dye penetrant and ultrasonic inspection methods respectively. The cement kiln plates were made out of heat resistant low alloy steel.

In dye penetrant inspection, the surfaces were cleaned using water, dried by cloth rags before the application of the dye penetrant. The dye was left on the joint for $20-30$ minutes before being cleaned off using wet cloth rags. Then the developer was applied and left for $10-15$ minutes before the area being inspected visually. All areas suspected to have cracks were marked for further investigation using Ultrasonic-testing equipment with compression and $45^{\circ}$ angle probes of 10 and $20 \mathrm{~mm}$ in diameters. Ultrasonic probes had frequencies of 2 and $4 \mathrm{MHz}$. In order to stop the cracks from propagating during the repair process, at each end of the crack, a $12 \mathrm{~mm}$ diameter hole was drilled.

The crack occurred at $25 \mathrm{~mm}$ thick plate. In order to repair it, the area was gouged using arc-air to give and external and internal bevels as shown in Fig. 8. The area to be gouged was preheated at around 100 ${ }^{\circ} \mathrm{C}$ temperatures to prevent any crack propagation. The gouged bevel surfaces were ground to ensure that high carbon induced by gouging was removed.

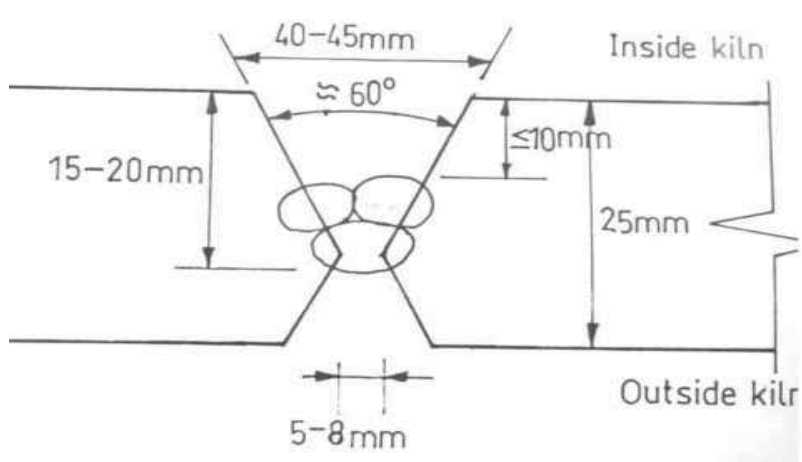

Fig. 8: Preparation of double bevel angles for the circumferential kiln shell joint

\section{FINDINGS AND DISCUSSIONS}

Very secure scaffolding was erected outside the kiln on circumferential welded joints for inspection. The through crack was investigated and it was found to be $640 \mathrm{~mm}$ in length. It was propagating through the weld metal. On the face of the weld metal, the visible cracks were extending up to $2030 \mathrm{~mm}$ (fig. 9 ). The kiln shell around the cracked joint plastically deformed due to excessive heat making the shell skin soft and due to restricted expansion of the kiln. The sharp edge of the joint were $25 \mathrm{~mm}$ plate met the $45 \mathrm{~mm}$ plate by welding was considered a stress concentration point, which is suspected to have initiated the cracking of the Kiln circumferential weld (fig. 10).

The ultrasonic crack inspection indicated that the through crack started from outside the kiln on a 25 $\mathrm{mm}$ plate weld fusion zone and propagated slanted through the weld metal to the $45 \mathrm{~mm}$ plate side of weld fusion zone inside the kiln shell for at least 500 $\mathrm{mm}$ length. The remaining length of $140 \mathrm{~mm}$ showed that the crack was perpendicular to the kiln axis. The partial cracks on the surface were found to have depth ranging from 5-15 mm. Cracks with depth less than $5 \mathrm{~mm}$ were repaired by grinding the area until the crack disappeared. Furthermore, all stress concentration raisers were removed from the weld joints by grinding off all reinforcement and blending in the joint with the immediate parent metal.

In order to reduce stresses on the cracked surface, the shell was rotated to the neutral position so that the crack was vertical to the ground. In this position, no tensile or compression stresses were encountered on the shell.

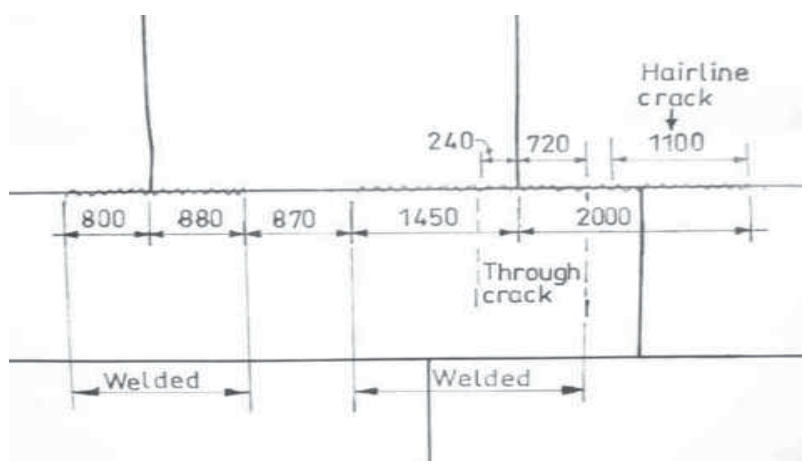

Fig. 9: The development of the kiln shell showing the affected areas. 
The through crack zone was gouged out to prepare the double bevel (Fig. 11). The gouged out area was inspected by dye penetrate method after grinding it to check if there is any crack. The plates to be welded were held together by strong stiffener before being preheated to a temperature of $100-150^{\circ} \mathrm{C}$ covering an area of $200 \mathrm{~mm}$ on either side of the crack, and the temperature was maintained in the welding zone during the repair (Table 3).

Table 3: Recommended Metal preheats temperatures for welding.

(Adapted and modified from STOODY Hard-facing Guidebook)

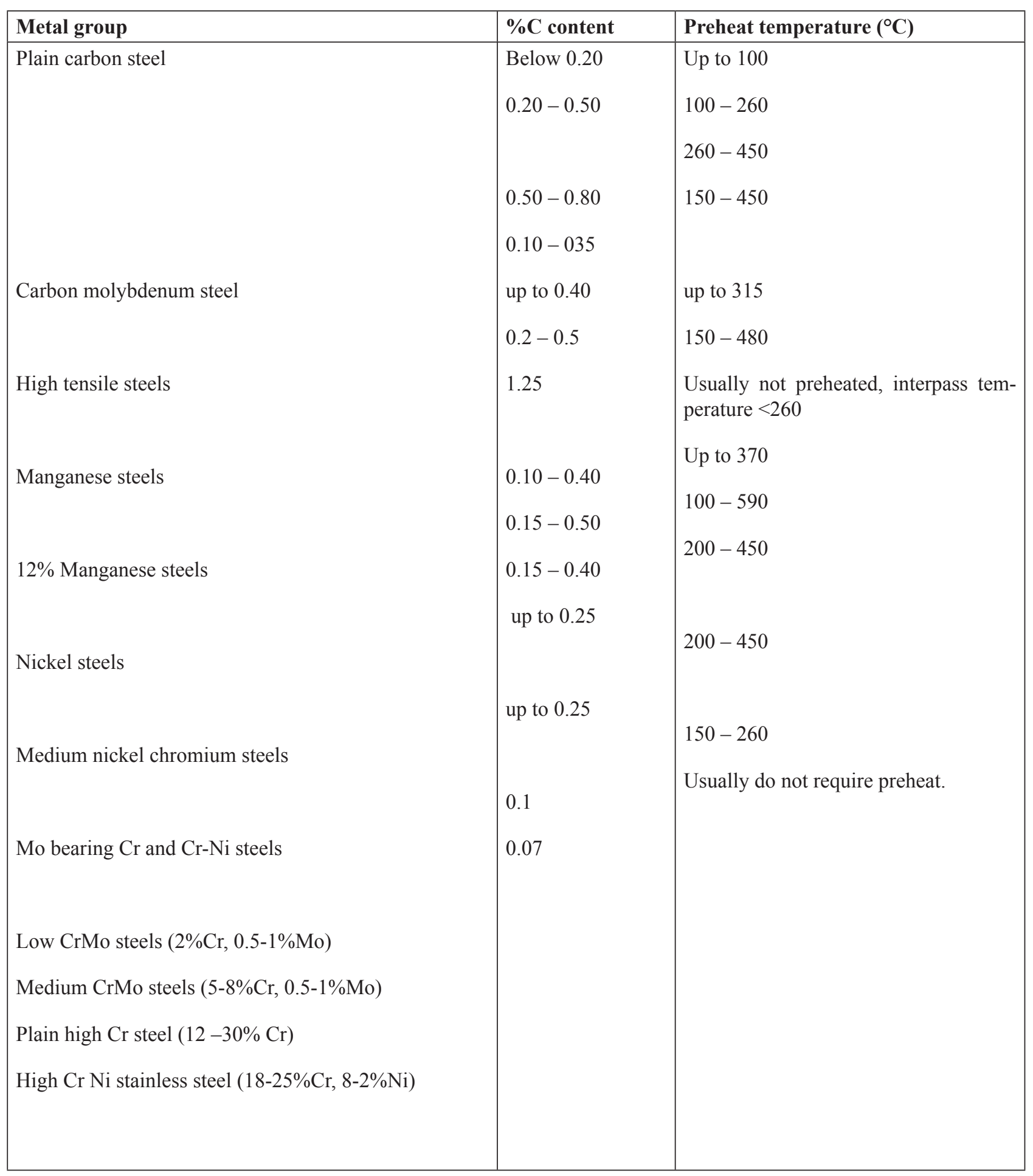


The selected electrodes for carrying out the repair work were E7018-1 electrodes. They were used for welding root, intermediate and capping passes with $3.2,4$ and $5 \mathrm{~mm}$ in diameters respectively. These electrodes are high quality basic electrode, particularly suitable for welding high strength low alloy steels. The typical weld metal is very resistant to hot cracking, with $30 \%$ elongation, $480 \mathrm{MPa}$ of yield strength and $590 \mathrm{MPa}$ of tensile strength (ESAB, 5thEd). Electrodes were baked in the oven at the temperature of $200-250^{\circ} \mathrm{C}$ for at least 2 hours before being transferred to the kiln in heated dry storage quiver. The welder started welding the outside bevel until completion. After that the inner part of bevel were ground off to remove dirty, inspected by dye penetrant to check for any crack and then welded using the same procedure. While welding, each layer deposited was hammered carefully over the whole length of the repair to relieve residual stresses and help in removing slag after every run. Any sticking slag was removed by grinding.

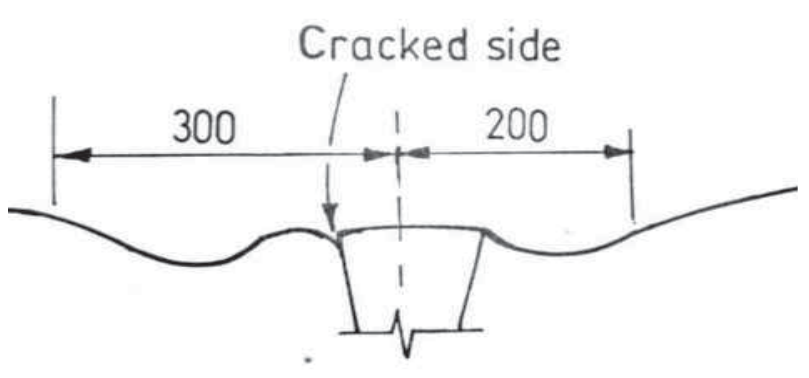

Fig. 10 Deformed shell at the welded joint.

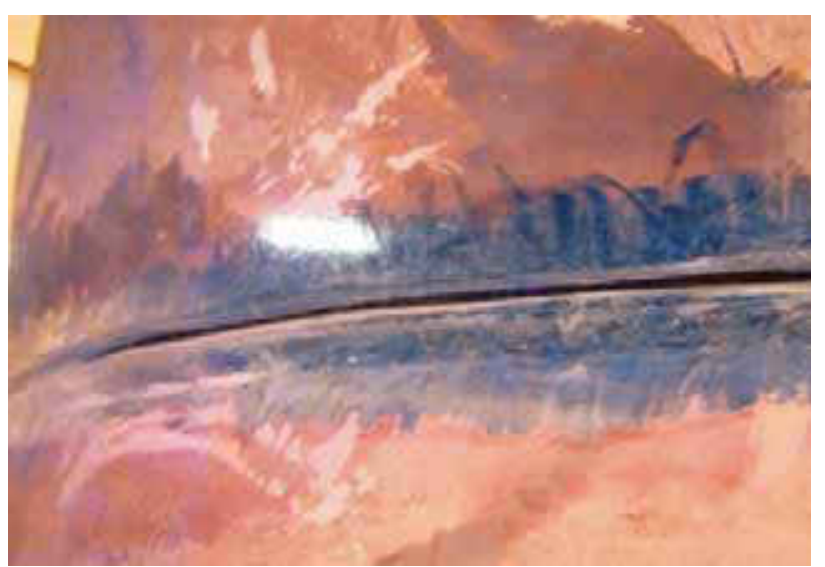

Fig. 11 Repairing of the cracked shell.
After complete welding, the joint was heated to about $100^{\circ} \mathrm{C}$ and soaked for about one hour by placing the insulation blankets in order to cool slowly and achieve the desired properties in the weld metal and heat affected zones. All deformed zones along the circumferential joint which failed by cracking were ground flat both inside and outside in order to avoid stress concentration points outside and to make sure that the refractory bricks inside the kiln are laid properly to make a perfect heat seal. All the welding was carried out by qualified (Technical) welders. Non destructive testing involving magnetic particle, dye penetrant was carried out to check if there were any cracks remaining in the circumferential welded joint.
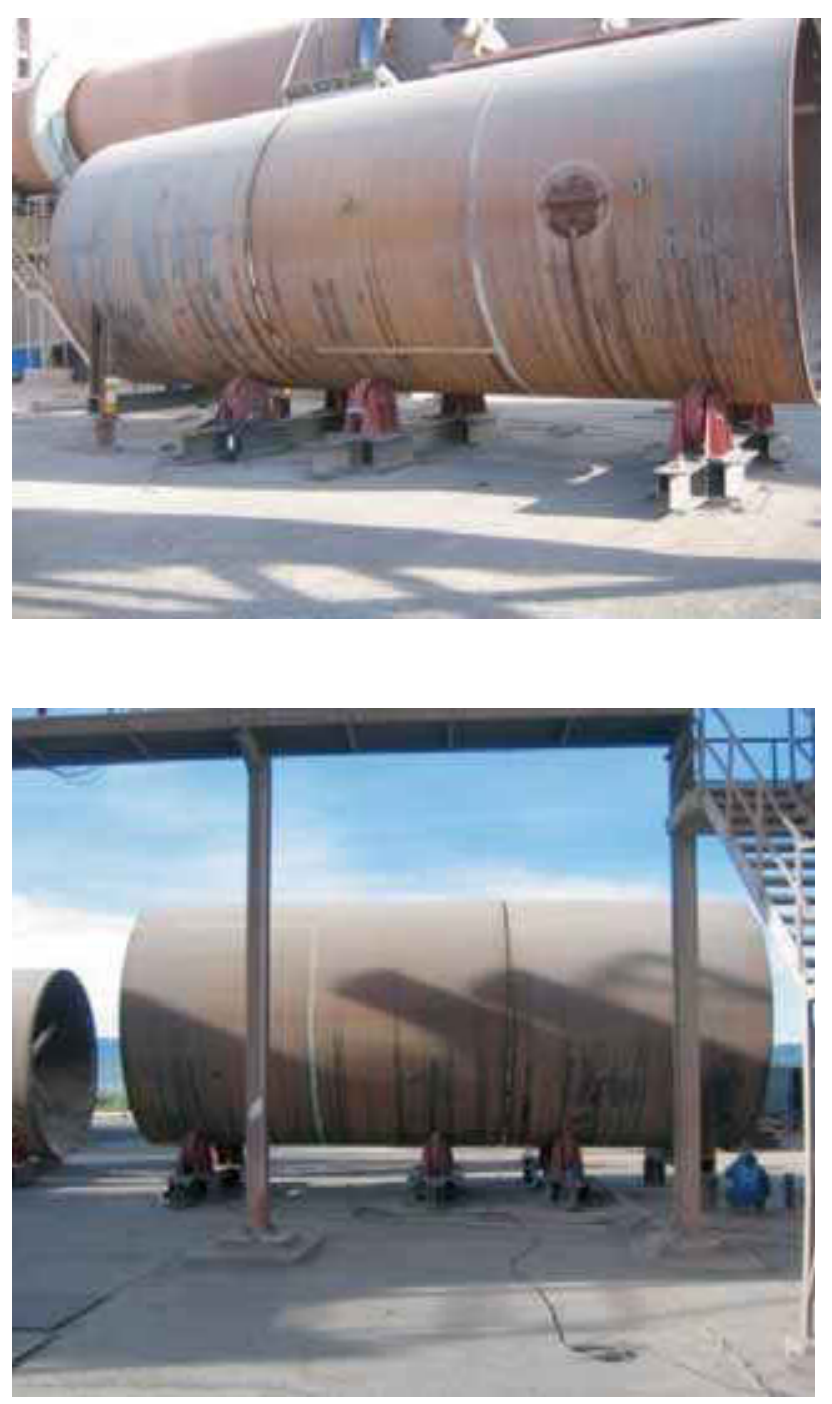

Fig. 12: New segments of kiln shell being welded on the ground before being hoisted into position. 
The repaired kiln was in use for two years before the new sections with increased plate thickness were installed by first cutting off the damaged segment of the kiln shell, then the new three segments were joined together on the ground and lifted into position as shown in Figs. 12. The author of this article was a welding consultant on both projects namely the repairing of the cracked shell and the installation of the new shell segments.

\section{CONCLUSIONS}

1. The through crack was $0.64 \mathrm{~m}$ long. The total length of the crack on the kiln was $2.03 \mathrm{~m}$.

2. The failure was caused by uneven deformation of the kiln at the cracked joint that in turn would have been caused by a number of other factors.

3. Equipment made out of steels with good weldability can be repaired successfully when proper welding and inspection procedures are observed as presented in these two case studies.

4. Local technical staff was used to supervise the preparation and welding of the structures with expatriates overseeing the exercise.

\section{The summary of two case studies}

The case studies show that all failures occurred due to fatigue failure. The first type of fatigue failure was due to the failure of roller bearing. Failure of the bearing may be due to lack of lubrication, shaft misalignment, inclusion of hard particles into the bearing rotating space, or fatigue due to the bearing running over its specified lifespan. The failure is usually accompanied by overheating and noise. The second failure is due to overheating of the kiln shell to the extent that it deformed. This caused it not to turn truly to its axis, and therefore induced the fluctuating stresses which started cracking at the stress concentration point. In this case it was the weld metal fusion line. Unlike the first case where the fractured bearing worn out the shaft journal and bearing housing, the kiln was opening up, and if the crack was unchecked in time, the $58 \mathrm{~m}$ long kiln would have bent or snapped off.

After failing to stop fatigue cracking, the remaining work was to properly carry out the repairs. The safety and economy of many people depended on the successful rebuilding of the equipment. Proper programme of maintenance of equipment may be costly, but not having proper maintenance has been costlier as exemplified in these two cases.

\section{ACKNOWLEDGEMENTS:}

The author takes this opportunity to thank the following: Tanzania International Container Terminal Services, Lafarge Mbeya Cement Co. Ltd and the University of Dar es salaam in assisting in one way or another in the preparation of this article.

\section{REFERENCES}

ESAB Welding Handbook 5th Edition "Filler materials for manual and automatic welding" ESAB AB, GOTEBORG SWEDEN

STOODY, Hard-facing Guidebook $5^{\text {th }}$ Edition 